\title{
TITLE:
}

\section{$<$ Note> Bossou Chimpanzees Crossed the National Border of Guinea into Liberia}

AUTHOR(S):

Ohashi, Gaku

CITATION:

Ohashi, Gaku. <Note> Bossou Chimpanzees Crossed the National

Border of Guinea into Liberia. Pan Africa News 2006, 13(1): 10-12

ISSUE DATE:

2006-06

URL:

http://hdl.handle.net/2433/143459

RIGHT:

Copyright (C) Pan Africa News. 
in the southeastern corner of the Republic of Guinea $^{1}$. The core area of the group consists of four small hills that are located about 4 $\mathrm{km}$ east from the Nimba Mountains. Due to the small core area and large distance of the Nimba Mountains, the Bossou group is thought to be geographically isolated from others. Secondary forests and abandoned fields cover over the border between Guinea and Liberia. Here I report the first observed case in which Bossou chimpanzees actually crossed the national border into the Liberian forest. Locations were recorded by GPS.

\section{OBSERVATIONS}

At 7:23, on February 14th, 2006, eleven chimpanzees, including my focal individual (PE, an adolescent male), were found eating Myrianthus libericus fruits $\left(7^{\circ} 38^{\prime} 19.3^{\prime \prime} \mathrm{N}, 8^{\circ}\right.$ $\left.30^{\prime} 48.0^{\prime \prime} \mathrm{W}\right)$. Next, they rested on the ground for a while. At 8:29, they started to move on the ground. Due to the heavy bush, the local assistants and I lost the chimpanzees at 8:39. At 10:47, we found the focal chimpanzee again $\left(7^{\circ} 38^{\prime} 07.7^{\prime \prime} \mathrm{N}, 8^{\circ} 30^{\prime} 55.2^{\prime \prime} \mathrm{W}\right)$. The party consisted of six chimpanzees: three adult males (TA, FF, and YL), two adult females (Pm and Yo), and one adolescent male (PE). They were resting on the ground, but they soon started to move. At 10:58, the six chimpanzees entered a swamp, and ate Nephrolepis biserrata leaves for about 5 minutes $\left(7^{\circ} 38^{\prime} 09.7^{\prime \prime} \mathrm{N}, 8^{\circ}\right.$ $\left.30^{\prime} 57.6^{\prime \prime} \mathrm{W}\right)$. They moved again and arrived at a pineapple field (7०37'53.9" N, 8०31'11.8" W). The field is located on the western slope of a hill called Zono, which Bossou chimpanzees often visit during consortship periods. For about 10 minutes, they ate pineapple fruit before entering the forest. At 11:46, three chimpanzees (YL, Yo, and Pm) started to eat Pseudospondias microcarpa fruit, and the other chimpanzees rested on the ground $\left(7^{\circ}\right.$ 37'56.3" N, 8०31'13.1" W). At 12:23, the six chimpanzees climbed the hill, and arrived at another Pseudospondias microcarpa tree at 12:52 (7³7'45.0" N, 8³1'27.6" W). They ate fruit and rested in the tree. At 14:14, they stared to move on the ground again. On the way, at 14:43, Yo started to eat Pennisetum

Since 1976, a group of wild chimpanzees has been studied at Bossou, which is located 


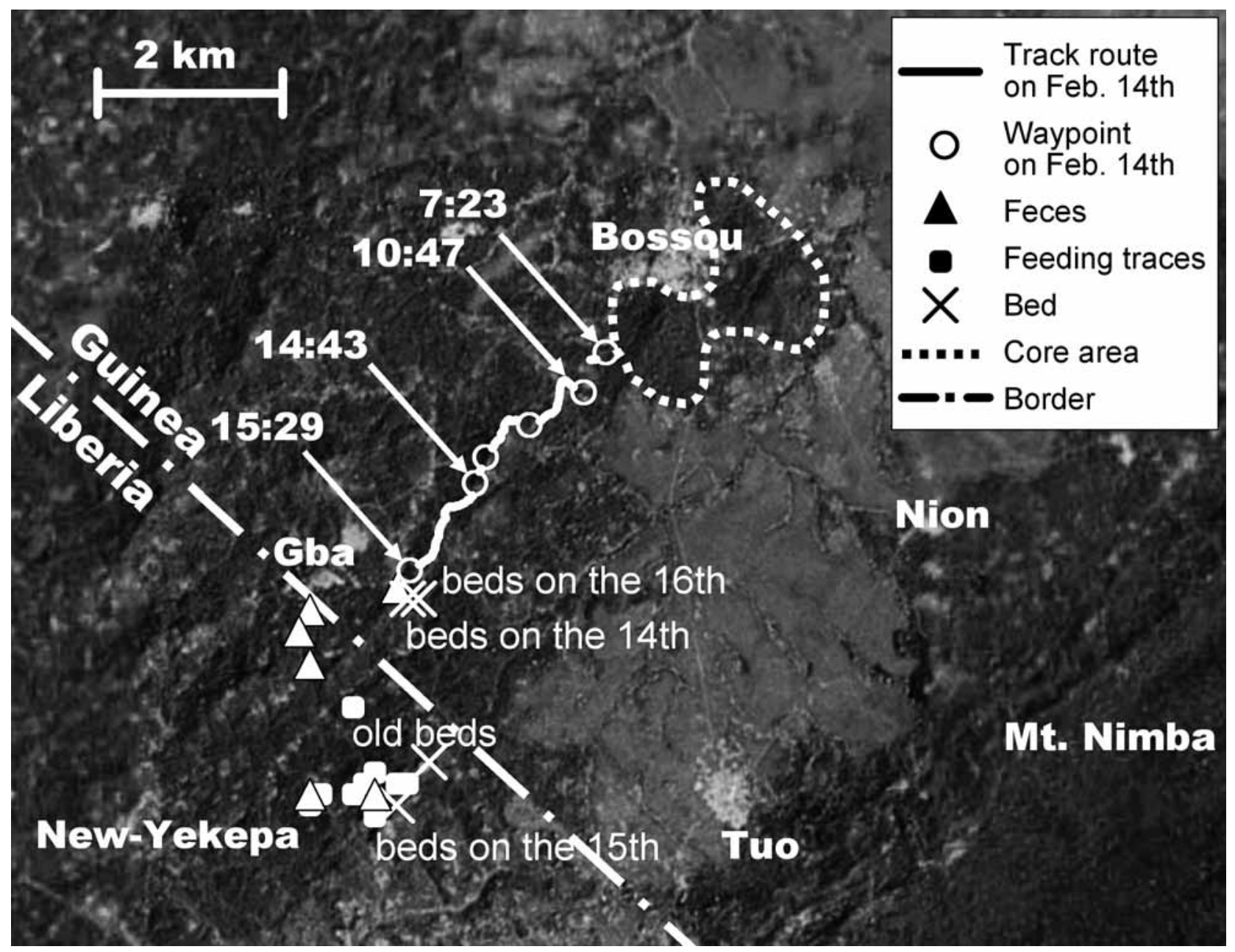

Fig. 1. Survey map of Guinea and Liberia (modified from Google Earth image).

purpureum pith, but the other five chimpanzees continued to travel $\left(7^{\circ} 37^{\prime} 36.7^{\prime \prime} \mathrm{N}, 8^{\circ} 31^{\prime} 30.8^{\prime \prime}\right.$ $\mathrm{W})$. The five chimpanzees entered the primary forest at the Gba village, Guinea. Gba is on the border with Liberia. At 15:27, three adult males (TA, FF, and YL) uttered pant-hoot, climbed trees, and traversed a valley. Since the forest over the valley appeared to be a sacred area of the village, we stopped following them at 15:29 (7॰37'03.6" N, 8³1'57.3" W).

On February 15 th, we looked for the chimpanzees in the $\mathrm{Gba}$ village. We found six beds there $\left(7^{\circ} 36^{\prime} 57.0^{\prime \prime} \mathrm{N}, 8^{\circ} 31^{\prime} 56.3^{\prime \prime} \mathrm{W}\right)$. Judging from the fresh feces under the beds, they apparently slept there from the evening of the 14th to morning (Fig. 1, beds on the 14th). When we visited the hill near the Liberian border, we found feces at the top $\left(7^{\circ} 36^{\prime} 58.2^{\prime \prime}\right.$ $\mathrm{N}, 8^{\circ} 31^{\prime} 57.3^{\prime \prime} \mathrm{W}$ ), but we could not find any chimpanzees in the Gba village.

On February 16th, six new beds (Fig. 1, beds on the 15th), fresh traces, and feces were found in the forest at New-Yekepa, Liberia $\left(7^{\circ}\right.$ $\left.35^{\prime} 45.8^{\prime \prime} \mathrm{N}, 8^{\circ} 31^{\prime} 59.1^{\prime \prime} \mathrm{W}\right)$. Judging from the traces, the chimpanzees appeared to have eaten sugar cane pith, Parkia fruit, Landolphia fruit, Myrianthus fruit, pineapple fruit, Aframomum pith and fruit, and palm petiole. We also found two old beds $\left(7^{\circ} 36^{\prime} 00.1^{\prime \prime} \mathrm{N}, 8^{\circ} 31^{\prime} 47.3^{\prime \prime} \mathrm{W}\right.$. Fig. 1 , old beds).

On February 17 th, four new beds were confirmed in the Gba forest $\left(7^{\circ} 36^{\prime} 57.3^{\prime \prime} \mathrm{N}, 8^{\circ}\right.$ $31^{\prime} 53.4$ " W. Fig. 1, beds on the 16th). Judging from the beds, the six chimpanzees returned to the Guinean side on the evening of the16th. At 13:23, TA, Pm, and PE were observed eating Morus mesozygia fruit at the core area of Bossou ( $\left.7^{\circ} 38^{\prime} 30.1^{\prime \prime} \mathrm{N}, 8^{\circ} 30^{\prime} 26.7^{\prime \prime} \mathrm{W}\right)$. At $14: 58$, all six chimpanzees were confirmed in the same Morus tree.

\section{DISCUSSION}

In February, fruits were abundant in 
the forest at Bossou ${ }^{2}$. Actually many trees bore their fruits, including Pseudospondias microcarpa, Morus mesozygia, Parkia bicolor, and Myrianthus libericus. The chimpanzees apparently did not travel to the peripheral area due to a lack of food. There are many sugar cane plantations in Liberia for distilling alcohol. Possibly their strong preference toward sugar cane tempted the chimpanzees into the Liberian forest.

Old beds were also found in the forest at New-Yekepa, Liberia. It suggests that Bossou chimpanzees had previously visited the forest. In this case, the chimpanzees only stayed in Liberia for two days. Due to the short stay and the difficulty of observation on the peripheral areas, researchers have probably missed traveling patterns.

According to the local people, chimpanzees exist in the northern part of Liberia. However, the distribution of chimpanzees there is almost unknown. Bossou chimpanzees may emigrate from Guinea to Liberia. As well as in Ivory Coast ${ }^{3}$, further extensive survey and conservation effort are needed in Liberia.

\section{ACKNOWLEDEGIMENTS}

This study was financed by a MEXT Grant-
in-Aid for Specially Promoted Research (nos.12002009, 16002001 to T. Matsuzawa), and a Grant-in-Aid for JSPS Research Fellow (no. 160896 to G. Ohashi).

\section{REFERENCES}

1.Sugiyama Y, Koman J. 1979. Social structure and dynamics of wild chimpanzees at Bossou, Guinea. Primates 20: 323-339.

2.Yamakoshi G. 1998. Dietary responses to fruit scarcity of wild chimpanzees at Bossou, Guinea: Possible implications for ecological importance of tool use. Am J Phys Anthropol 106: 283-295.

3.Humle T, Matsuzawa T. 2001. Behavioural diversity among the wild chimpanzee 